\title{
Technological Disruption and Music Copyright
}

\author{
Victoriano Darias \\ Berklee College of Music (Valencia)
}

This paper was presented at the 2019 International Summit of the

Music \& Entertainment Industry Educators Association

March 21-23, 2019

\section{$\underline{\text { https://doi.org/10.25101/19.38 }}$}

\section{Abstract}

You can take any catalogue of records of any talking machine company in this country and you will find from 20 to 100 of my compositions. I have yet to receive the first penny for the use of them. (Rosenlund 1979, 686)

American March King, John Philip Sousa, expressed himself in the above terms before the Committee of Patents of the U.S. Senate and House of Representatives in 1906, during the preparatory work for the 1909 U.S. Copyright Act. In 2000, Metallica drummer Lars Ulrich, made the following contents before the U.S. Senate Judiciary Committee during a hearing on music downloads:

Napster hijacked our music without asking. They never sought our permission. Our catalog of music simply became available as free downloads on the Napster system.

The two statements are almost a century apart and yet the complaint is almost identical: there is a new technology that is being used by certain companies to make music available without remunerating creators. As we can therefore see, and contrary to popular belief, the internet has not been the only technology to create a disruption in an industry like the music business that relies on copyright protection. This paper examines different technologies that had a disruptive effect on the entertainment industry in general, and music in particular, analyzing the legal solution that was implemented. We will discuss the importance of this disruptive effect, and we will argue that in the case of the internet it is of lesser magnitude than that of previous technological advancements. We will also see that there are many similarities between the arrival of the internet and that of other technologies, both in the effect that they had on the industry and in the legal solution adopted, which generally meant extending copyright protection to the newly developed forms of exploitation. However, we will also comment on a major difference: how quickly, at least in comparison to previous technological advancements, legislation was passed in order to regulate copyright in the internet, and we will argue that this swiftness might have paved the way for online services to be developed after its adoption that benefited from legal loopholes.

Keywords: music copyright, technological disruption, music downloading, music streaming

Victoriano Darias is a music industry veteran from Spain who has worked for the International Federation of the Phonographic Industry (IFPI) and the European Grouping of Societies of Authors and Composers (GESAC). While he stills consults and provides legal advice to a variety of clients, including songwriters and artists, trade associations, and content producers, he has developed in the past five years a career in academia. He currently combines his role of Director of Academic Affairs at Berklee College of Music (Valencia campus) with the teaching of courses on the music industry, its legal aspects, and music and the media. $\mathrm{He}$ is also the program director of the Master in Intellectual Property \& IT Law at Universidad Internacional de La Rioja (UNIR), Spain. Darias holds a Ph.D. from Universidad de La Laguna (Spain), a Master in Music Business (M.A.) from New York University, and another one in European Union Law (LLM) from the College of Europe (Belgium) He has published two books in Spanish, one on the legal aspects of music in the internet, and a second one on music and the media.

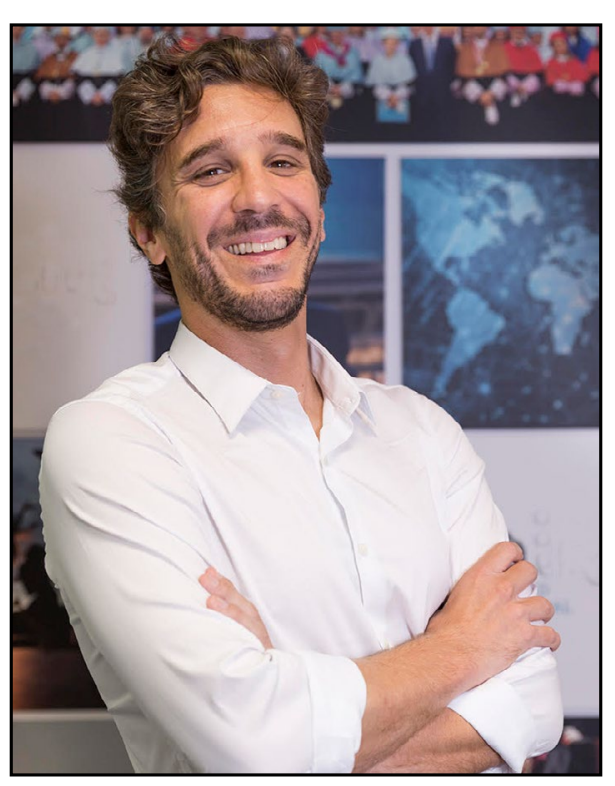




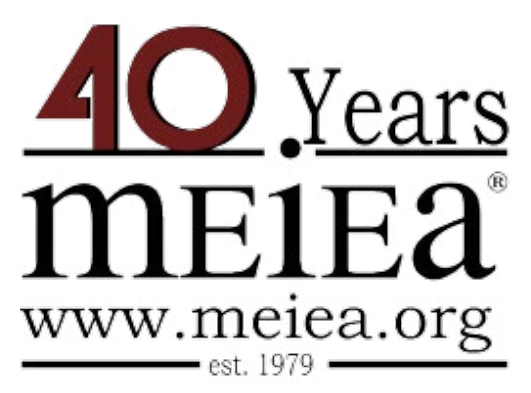

\section{PROCEEDINGS OF THE \\ 2019 INTERNATIONAL SUMMIT \\ OF THE \\ MUSIC \& ENTERTAINMENT \\ INDUSTRY EDUCATORS \\ ASSOCIATION}

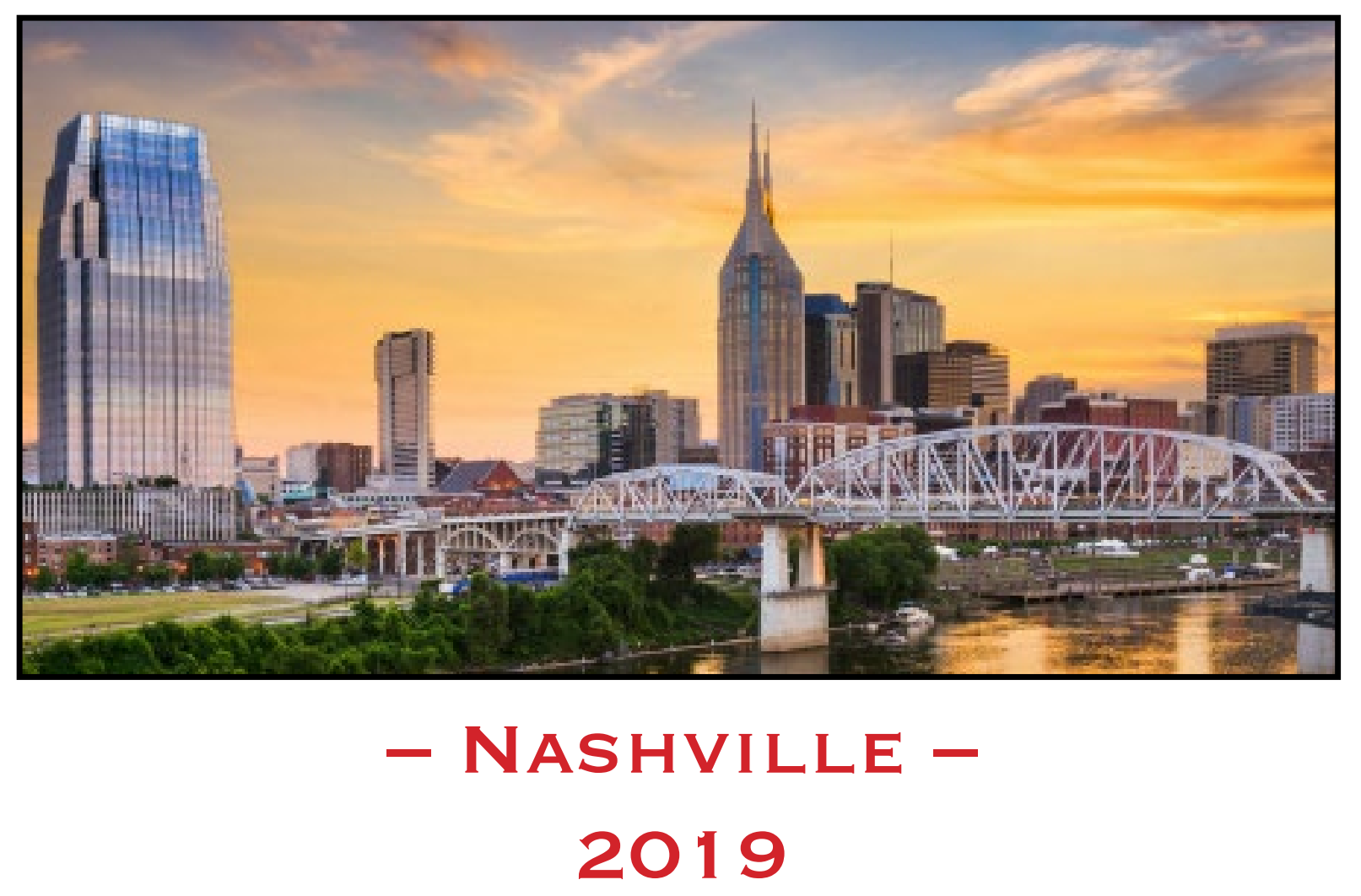

March 21 - 23, $2019 \cdot$ Belmont University - Nashville 